\title{
IDENTIFICAÇÃO DE MICROCISTINA LR AO NÍVEL MOLECULAR EMPREGANDO MICROSCOPIA DE FORÇA ATÔMICA
}

\author{
Augusto Etchegaray* e Carolina de Castro Bueno \\ Faculdade de Química, Pontifícia Universidade Católica de Campinas, CP 317, 13012-970 Campinas - SP, Brasil \\ Omar Teschke \\ Instituto de Física Gleb Wataghin, Universidade Estadual de Campinas, CP 6165, 13083-970 Campinas - SP, Brasil
}

Recebido em 21/10/09; aceito em 15/6/10; publicado na web em 22/9/10

\begin{abstract}
IDENTIFICATION OF MICROCISTIN LR AT THE MOLECULAR LEVEL USING ATOMIC FORCE MICROSCOPY. Microcystins are non-ribosomal peptides that must be detected for its health concern. Here, microcystin LR and its specific antibody were respectively tethered to the substrate and to the tip of an atomic force microscope, after surface functionalization using 3-aminopropyltriethoxysilane and glutaraldehyde. Functionalization was confirmed comparing topographic images taken on bare and modified tips. Force versus distance curves were successfully used to measure the specific antibody-antigen interactions comparing with a control in which microcystin was initially blocked by incubation with free antibodies. The results showed unequivocally the specific recognition of MLR, suggesting that this method could be useful for biosensor development.
\end{abstract}

Keywords: microcystin LR; atomic force microscope; biosensor development.

\section{INTRODUÇÃO}

Relatos de intoxicação animal e de doenças em seres humanos ligadas a toxinas de cianobactérias ocorrem no mundo todo. No Brasil, foi registrada a morte de 50 pacientes de hemodiálise em uma clínica de Caruaru (Pernambuco), cujos tanques de hemodiálise haviam sido lavados com água contaminada com microcistinas. ${ }^{1}$ Apenas este relato demonstra a necessidade de um método sensível de detecção para proteção da saúde pública e na gestão dos recursos hídricos, onde há grande propensão de desenvolvimento de florações tóxicas. ${ }^{2}$ Vários métodos de detecção são utilizados atualmente, como a cromatografia líquida de alta eficiência acoplada à espectrometria de massas, bioensaios envolvendo animais de laboratórios, testes de inibição enzimática e testes imunológicos. ${ }^{2,3}$

Cianobactérias produtoras de toxinas são conhecidas por cianobactérias tóxicas, como algumas linhagens de Microcystis, Anabaena, Oscillatoria e Cylindrospermopsis. ${ }^{4} \mathrm{O}$ estresse abiótico pode levar as cianobactérias a produzirem toxinas como as microcistinas, uma família de hepatoxinas, altamente perigosas para a saúde de seres vivos. Existem mais de 70 isoformas de microcistinas, com graus diferentes de toxidade. ${ }^{5,6}$ Estas toxinas são peptídeos não ribossômicos cíclicos com pequenas diferenças estruturais, entre eles a microcistina LR (MLR), microcistina RR, microcistina YR e nodularina, sendo MLR considerada a mais tóxica ${ }^{5-7}$ MLR é um inibidor de fosfatases de proteínas que apresenta toxicidade considerável para mamíferos, podendo levar à lesão total do fígado. ${ }^{1,2}$

Desde que a MLR foi encontrada em águas salgadas, estudos adicionais têm sido reportados para a determinação dessas toxinas. ${ }^{8}$ Considerando-se a sensibilidade e especificidade da interação antígeno-anticorpo (Ag-Ac) e sua aplicação em diversos sistemas de diagnósticos, o método imunológico também tem sido empregado com sucesso na detecção de microcistinas, ${ }^{9}$ incluindo-se biossensores. ${ }^{10}$

A imunodetecção baseia-se em interações moleculares específicas de curto alcance, envolvendo o reconhecimento Ag-Ac. A interação entre proteínas e receptores específicos também envolve forças semelhantes. Em anos recentes, sistemas envolvendo interações mo-

*e-mail: augusto.etchegaray@puc-campinas.edu.br leculares específicas têm sido explorados através da microscopia de força atômica (AFM). O trabalho de Ferreira e Yamanaka apresenta uma excelente revisão sobre o assunto. ${ }^{11}$ Como a AFM é baseada na varredura de uma superfície com uma ponta, é possível explorar as forças de interação entre elas através de sondas específicas. ${ }^{12}$ Existem diversos trabalhos com AFM envolvendo o reconhecimento específico de antígeno em uma superfície, a partir da funcionalização de uma ponta com anticorpos. ${ }^{13}$

AFM também tem sido utilizada para estudos de viscosidade e elasticidade de materiais. Além de produzir imagens de superfície, esta técnica pode ser aplicada no estudo de forças envolvidas em interações atrativas ou repulsivas. Para tanto, há uma ferramenta chamada espectroscopia de força, que é um método alternativo para se obter informações sobre o rompimento de interações do tipo receptorligante. Esta medição tem sido amplamente utilizada para o estudo de diferentes sistemas biológicos, incluindo interações Ag-Ac. ${ }^{13}$

Neste trabalho, MLR foi acoplada com sucesso sobre a superfície da mica muscovita, usando um método de derivatização com 3-aminopropiltrietoxissilano e glutaraldeído. ${ }^{14}$ A mesma estratégia foi utilizada para a funcionalização das pontas de nitreto de silício com moléculas de anticorpo. Imagens no modo não contato, feitas no ar, confirmam a fixação de microcistina à superfície da mica após varredura com uma ponta normal e com uma ponta contendo anticorpos específicos contra MLR. Curvas de força em função da distância também foram medidas, demonstrando o reconhecimento específico de microcistina LR. Sinais de reconhecimento através de curvas de força tornam-se inexistentes quando a superfície contendo antígenos é previamente tratada com anticorpos, confirmando a validade dos resultados. Este é o primeiro relato do reconhecimento molecular de microcistina utilizando AFM.

\section{PARTE EXPERIMENTAL}

\section{Funcionalização das pontas e do substrato}

A funcionalização dos substratos (mica muscovita, New York Co. Nova Iorque, EUA) e das pontas de nitreto de silício, respectivamente com MLR e com anticorpos, foi feita a partir de um método que 
envolve primeiramente a silanização da superfície com 3-aminopropiltrietoxissilano (APTES), seguida de reação com glutaraldeído. ${ }^{14}$ As reações foram feitas em uma câmara de reação consistindo de um dessecador com entrada e saída para argônio, para remover oxigênio e partículas de poeira de dentro da câmara. Foram colocadas em uma placa de Petri estéril com divisórias as amostras de mica e pontas de $\mathrm{Si}_{3} \mathrm{~N}_{4}$ para esterilização sob luz ultravioleta (15 min). Dentro do dessecador, foram adicionados em tampas de tubos Eppendorf, respectivamente, $40 \mu \mathrm{L}$ de APTES, (99\% - Sigma-Aldrich, St. Louis, MO) e $30 \mu \mathrm{L}$ de trietilamina (99\% - Sigma-Aldrich, St. Louis, MO). A placa de Petri contendo o substrato e as pontas foi imediatamente inserida no dessecador. Com o sistema pronto, o fluxo de argônio foi interrompido, deixando-se o sistema fechado por 30 min para o ataque de APTES à superfície da mica e das pontas. Após a exposição ao vapor de APTES, $200 \mu \mathrm{L}$ de uma solução aquosa de glutaraldeído $1 \times 10^{-3} \mathrm{~mol} \mathrm{~L}^{-1}$, preparado a partir de uma solução concentrada (Grad I: $25 \%$ Aqueous Solution - Sigma-Aldrich, St. Louis, MO), foram adicionados sobre as placas de mica e sobre as pontas de nitreto de silício e o sistema foi incubado por $10 \mathrm{~min}$. Decorrido este tempo, foram feitas 4 lavagens com água MilliQ. Para completar a funcionalização adicionaram-se $25 \mu \mathrm{L}$ da solução de anticorpo anti-MLR (concentração de proteína $\sim 2,6 \times 10^{-6} \mathrm{~mol} \mathrm{~L}^{-1}$ ) sobre cada ponta e $30 \mu \mathrm{L}$ do padrão de MLR ( $\left.2 \mu \mathrm{g} \mathrm{L}^{-1}\right)$ sobre cada superfície de mica. Estas amostras foram incubadas durante $25 \mathrm{~min}$ sob atmosfera de argônio, à temperatura ambiente. Após esse período, foram feitas várias lavagens com água MilliQ. Após remoção da última lavagem com água, pontas e substratos foram armazenados em um dessecador antes da análise por AFM.

\section{Microscopia de força atômica e espectroscopia de força}

O microscópio de força atômica ThermoMicroscope AutoProbe $\mathrm{CP}$ foi utilizado nos modos contato e não contato. $\mathrm{O}$ modo não contato foi utilizado para obtenção de imagens topográficas. Experimentos de varredura no modo não contato com pontas normais e funcionalizadas com anticorpo foram realizados a uma distância de aproximadamente $30 \mathrm{~nm}$ da superfície da amostra, com frequência de oscilação e amplitudes apropriadas, de acordo com instruções do fabricante. A calibração das alavancas foi feita de acordo com o método descrito por Sader et al., submetendo-se o sistema à vibração e medindo-se a frequência de ressonância no ar. ${ }^{15}$ Determinações feitas a cada lote apresentam pequenos desvios do valor nominal ( 20\%). Foram calibradas apenas as alavancas com pontas normais. As pontas funcionalizadas não foram recalibradas.

O modo contato foi utilizado para determinação de curvas de força. Todas as análises foram realizadas em tampão fosfato de sódio $20 \times 10^{-3} \mathrm{~mol} \mathrm{~L}^{-1}, \mathrm{pH} \mathrm{7,4}$. Apenas um substrato funcionalizado com microcistina LR foi utilizado para as medidas. As sondas com anticorpos foram preparadas a partir da funcionalização de 10 alavancas com pontas de contato. Devido à fixação de antígenos à sonda durante as medidas, foram feitas apenas 3 determinações para cada sonda, totalizando 30 medidas. Todas as medidas foram obtidas por dois ciclos com taxa de varredura de $0,043 \mathrm{nA} \mathrm{nm}^{-1}$ e com pontas de $\mathrm{Si}_{3} \mathrm{~N}_{4}$ apropriadas para o modo de contato (constante de mola igual a $0,03 \mathrm{~N} / \mathrm{m}$ ). Para análise foram utilizados os programas TopoMetrix SPMLab 4.0 e Microcal Origin 6.0.

\section{RESULTADOS E DISCUSSÃO}

\section{Estudo topográfico do padrão de MLR por AFM}

Os experimentos de varredura foram feitos no modo não contato, ao ar, em uma atmosfera com cerca de $60 \%$ de umidade, a tempe- ratura ambiente. Nestas condições, embora as amostras e pontas estivessem inicialmente armazenadas em um dessecador, ao adaptálas às condições de varredura, haverá formação de uma camada de água sobre a superfície da amostra e da sonda. ${ }^{16}$ As forças exercidas no modo não contato são extremamente fracas. Entretanto, no caso de amostras biológicas, a proximidade e a existência de água entre a ponta e a superfície poderão contribuir para o desenvolvimento de interações de especificidade química, principalmente a do tipo antígeno-anticorpo. ${ }^{9,10}$

O preparo da amostra para análise envolveu primeiramente o ataque da superfície da mica com vapor de APTES na presença de vapor de trietilamina. Portanto, mesmo após as lavagens e tratamento com glutaraldeído, o pH na superfície da mica mantém-se neutro ou levemente básico, permitindo a reação com a cadeia lateral da arginina, aminoácido presente na estrutura da MLR (Figura 1S, material suplementar). Na funcionalização que precede a ligação da microcistina, ocorre inicialmente a formação de uma ligação covalente com a superfície do mineral através do grupamento silanol do APTES e grupamentos hidroxila presentes na superfície da mica. $\mathrm{Na}$ etapa seguinte é feito um tratamento com o reagente bifuncional glutaraldeído. ${ }^{14}$ Este deve reagir com o APTES ligado à mica, introduzindo uma extremidade reativa (grupamento aldeído) que pode reagir com aminoácidos básicos como a arginina, além de desempenhar a função como espaçador e dar flexibilidade à interação anticorpo-antígeno Ac-Ag. A funcionalização da ponta de nitreto de silício ocorre de forma semelhante. Neste caso, após tratamento com glutaraldeído, haverá ligação do anticorpo ao conjugado APTES-glutaraldeído através de aminoácidos, como lisina e arginina presentes na molécula de anticorpo (Figura 2S, material suplementar).

A Figura 1a apresenta uma imagem de varredura com ponta normal em uma região do substrato (área de $1 \mu \mathrm{m}^{2}$ ) onde se pode observar um pico contendo microcistina ligada à superfície da mica. $\mathrm{O}$ perfil desta imagem (Figura $1 \mathrm{~b}$ ) fornece as dimensões para o pico e vizinhanças, de onde se pode deduzir que a altura deste pico corresponde a $6,5 \mathrm{~nm}$. Tanto a imagem como o perfil sugerem a existência de um patamar com cerca de $0,5 \mathrm{~nm}$ de altura, correspondendo ao APTES (Figura 1b). Baseando-se no número de ligações carbonocarbono e considerando a distância média de 0,1 a $0,15 \mathrm{~nm}$ para cada ligação, sugere-se a altura para uma monocamada de APTES entre 0,5 e $1 \mathrm{~nm}$ (Figura 1S, material suplementar). Da mesma forma, uma molécula de glutaraldeído pode ter uma altura de aproximadamente $1 \mathrm{~nm}$. A partir de dados da estrutura tridimensional da microcistina, disponíveis na base de dados de proteínas (PDB), estima-se que uma molécula apresente uma altura de $\sim 2 \mathrm{~nm}$, quando ligada a partir do aminoácido arginina. ${ }^{17}$ Considerando-se que uma molécula de microcistina poderia estar associada a outra por interação entre as cargas da cadeia lateral do ácido glutâmico (negativa) e da arginina (positiva), é possível ter um arranjo com duas moléculas, totalizando $\sim 4 \mathrm{~nm}$ (Figura 2S, material suplementar). Somados a um possível arranjo com polimerização de APTES-glutaraldeído de 2 a 2,5 nm, o total corresponde aos 6,5 nm de altura deste pico (Figura 1b). Um controle feito com o tratamento da mica depositando-se uma gota $(5 \mu \mathrm{L})$ de APTES diretamente sobre o substrato demonstra que o excesso deste reagente induz à formação de arranjos supramoleculares. Análise de um pico destas estruturas apresenta as dimensões de $20 \mathrm{~nm}$ de altura e base com $~ 500 \mathrm{~nm}$ de largura (Figura 3S, material suplementar). O tratamento com vapores de APTES também produz arranjos supramoleculares, porém as dimensões são menores. Adicionalmente, o ápice de um pico com microcistina acoplada é fino, quando comparado com as dimensões para um arranjo supramolecular formado por APTES (Figura 3S, material suplementar).

Observa-se uma baixa densidade de picos brilhantes possivelmente devido às condições de reação durante a funcionalização. A 


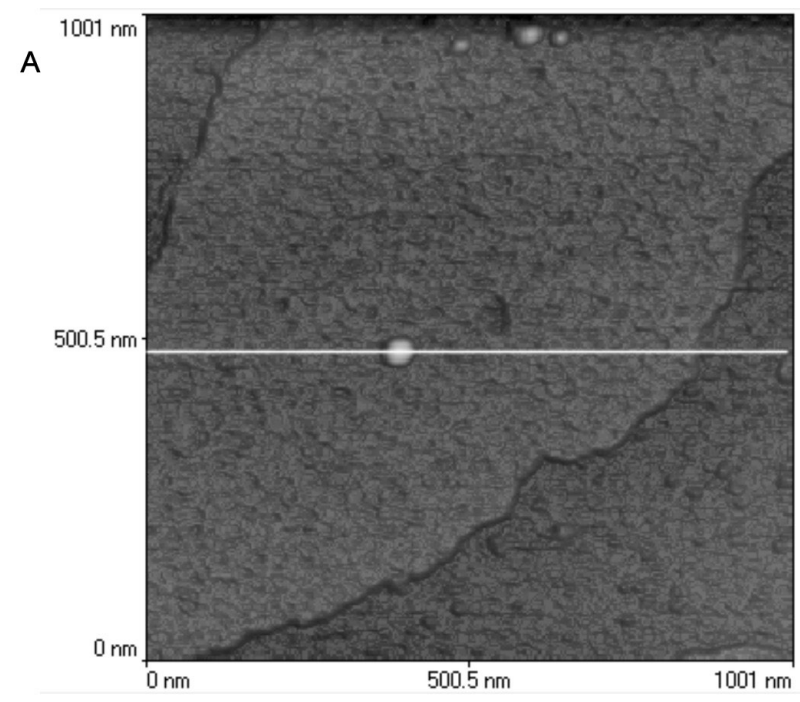

B

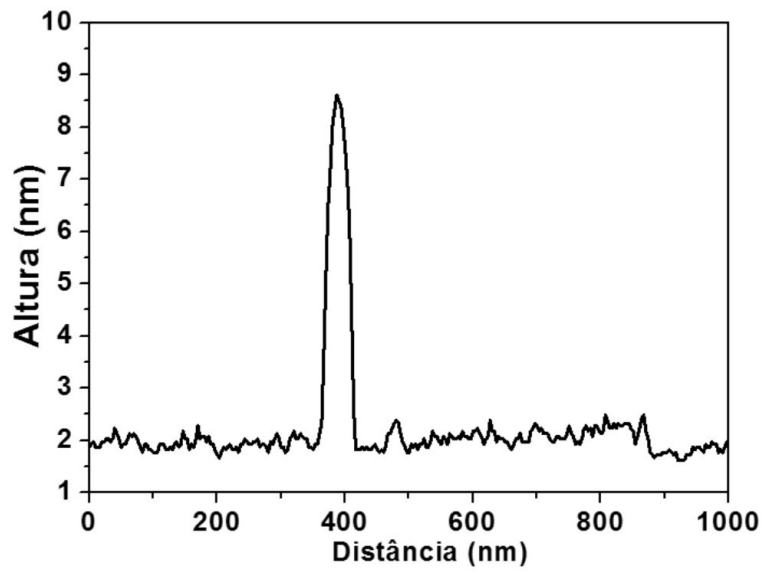

Figura 1. Imagem topográfica da superfície da mica após varredura com uma ponta não funcionalizada: (A) imagem correspondente a uma área de $1 \mu^{2}$ onde se identificam 4 pontos brilhantes. $O$ corte vertical (linha branca sobre a imagem) está apresentado em (B), de onde se obtém os valores de 6,5 nm para a altura do pico e verifica-se a existência de um degrau de cerca de 0,5 nm correspondendo à camada de APTES

etapa limitante corresponde ao intervalo de exposição aos vapores de APTES, que foi de $30 \mathrm{~min}$. Nestas condições poderá haver uma funcionalização parcial e heterogênea da superfície, com áreas mais expostas ou mais reativas do que outras. A reatividade na superfície do mineral pode ser diminuída em regiões da superfície que possuam uma monocamada de água, ${ }^{16}$ inibindo a reação do grupo silanol com sítios apropriados na superfície da mica. Estas condições favoreceram a identificação de sítios contendo microcistina, pois promoveram uma baixa densidade de sítios de ligação covalente entre o peptídeo e a superfície da mica. Os picos brilhantes correspondem às moléculas individuais de microcistina ligadas ao conjugado APTES-glutaraldeído. ${ }^{14} \mathrm{~A}$ solução padrão de microcistina utilizada $\left(2 \mu \mathrm{g} \mathrm{L}^{-1}\right)$ é bastante diluída para dispersão na área analisada. A área da mica inicialmente exposta aos vapores de APTES corresponde a aproximadamente $1 \mathrm{~cm}^{2}$. Considerando-se que foram feitas lavagens com água após cada etapa de funcionalização, apenas os sítios contendo APTES e glutaraldeído formaram ligações covalentes com a microcistina.

Considerando-se que a varredura com pontas funcionalizadas pode apresentar sinais associados a uma interação específica para o sistema anticorpo-antígeno, ${ }^{14}$ também utilizamos uma sonda de anticorpos (ponta funcionalizada) para a varredura do substrato contendo microcistina. A Figura 2a apresenta uma imagem topográfica resultante da varredura de uma área de $1 \mu \mathrm{m}^{2}$. A diferença entre as imagens das Figuras 1 e 2 parece estar principalmente na altura dos picos. Comparando-se o pico da Figura 1 com um dos picos da Figura 2, observa-se uma diferença de aproximadamente 1,5 nm de altura. Portanto, a varredura com a sonda de anticorpos pode gerar um pico mais alto. Uma possível explicação é que a presença do anticorpo aumenta o raio de curvatura da ponteira, produzindo uma ponta mais larga e irregular (Figura $2 \mathrm{~S}$, material suplementar). Como resultado, as imagens apresentam artefatos, gerando picos menos nítidos quando comparados com aqueles produzidos pela varredura com a ponta normal (Figura 4 S, material suplementar). A perda de nitidez poderia inclusive ser atribuída a um evento de reconhecimento específico entre a sonda e o substrato (Ac-Ag), haja vista que a proximidade entre ambos é maior, considerando-se que houve um aumento do raio de curvatura da ponta após a ligção de anticorpos e que a sonda foi mantida a uma altura constante de 30 nm durante a varredura.
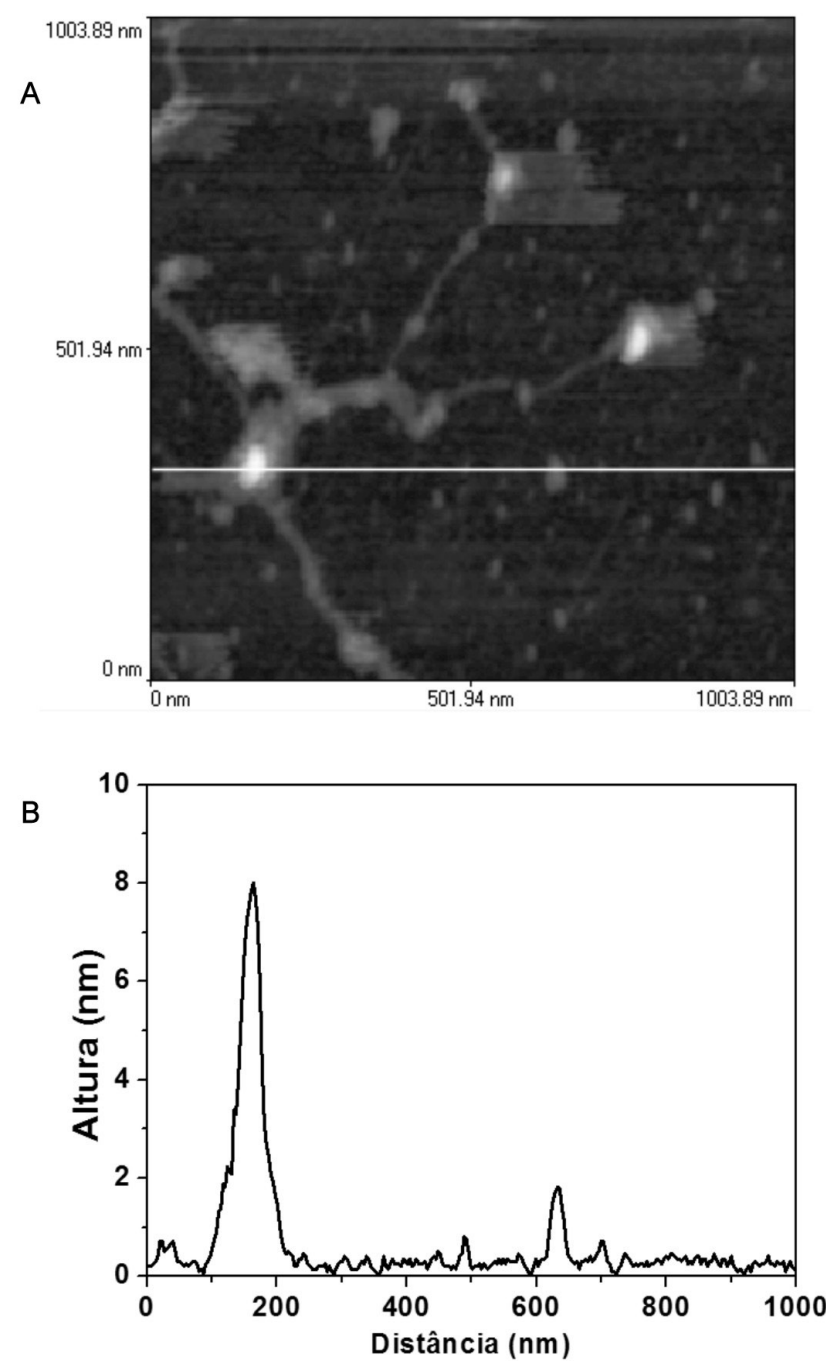

Figura 2. Imagem topográfica gerada com uma ponta funcionalizada com anticorpos. Na foto (A), que corresponde a uma área de $1 \mu^{2}$, visualizam-se 3 picos brilhantes, sendo que dois deles apresentam um arraste sugerindo que, embora a varredura seja feita no modo "não contato" houve um ponto de contato, gerando atrito entre a ponta e a amostra. O perfil vertical $(B)$, correspondendo a um corte da imagem na linha branca, fornece o valor para a altura de um dos picos identificados em (A) 
Embora este experimento tenha sido realizado no ar e no modo não contato, devido ao volume das moléculas de anticorpo acopladas à ponta, é possível que em alguns locais tenha ocorrido um evento de contato temporário entre a ponta e o substrato, gerando imagens com menor nitidez (Figura 4S, material suplementar).

\section{Curvas de força para o sistema anticorpo/MLR}

Curvas de força em AFM servem para quantificar interações entre a ponta e a amostra. As curvas de força apresentam dois componentes, uma curva de aproximação, caracterizada por um evento de repulsão, e uma curva de retração, que pode apresentar componentes negativos quando há interação química entre a ponta e o substrato. ${ }^{18,19}$ Neste trabalho, as análises no modo contato, envolvendo curvas de força em função da distância, confirmam a arquitetura do sistema e o reconhecimento específico microcistina/anticorpo.

Detalhes de uma curva de aproximação confirmam a arquitetura do sistema (Figura 3). Pelo menos três diferentes camadas depositadas sobre a mica podem ser identificadas. A curva indica que a ponteira toca a amostra a aproximadamente $6 \mathrm{~nm}$. A partir deste contato é necessário aumentar constantemente a força aplicada para vencer as camadas dos diferentes materiais depositados. Considerando-se as diferenças na taxa de incremento da força para transpor as camadas como um sinal de que existem materiais de constituição química diferente, sugere-se a seguinte interpretação: há uma camada de aproximadamente $2 \mathrm{~nm}$ correspondente a uma molécula de anticorpo ligada à ponta através do conjugado glutaraldeído/APTES (distância entre as linhas 1 e 2 indicadas na curva); há uma camada de aproximadamente $2 \mathrm{~nm}$ correspondente à molécula de microcistina (distância entre as linhas 2 e 3); antes da superfície da mica existem mais três camadas (3-4, 4-5 e 5-0, cada uma com aproximadamente $0,5 \mathrm{~nm}$, correspondente a arranjos moleculares de glutaraldeído e APTES. Para vencer a primeira camada (de 1 a 2) é necessário aplicar uma força crescente com valor máximo de aproximadamente $50 \mathrm{pN}$. A altura da molécula de anticorpo acoplada ao conjugado (glutaraldeído-APTES) corresponde a cerca de $2 \mathrm{~nm}$, conforme pode ser visto pela mudança na inclinação da curva, a aproximadamente $2 \mathrm{~nm}$ de distância do ponto de contato. Para vencer a próxima camada há um aumento da força para aproximadamente $150 \mathrm{pN}$, permanecendo praticamente constante por uma distância de cerca de $1,5 \mathrm{~nm}$ (2 a 3), que corresponderia a um evento de estiramento e transposição da molécula de microcistina. As distâncias percorridas entre as linhas 3 e 4 e 4 e 5 devem corresponder a camadas de glutaraldeído $(0,5 \mathrm{~nm})$ e, entre as linhas 5 e 0 , ao APTES $(\sim 1 \mathrm{~nm})$. O total neste caso corresponde a cerca de 5,5 $\mathrm{nm}$ para o arranjo APTES-glutaraldeído-microcistina, semelhante aos valores observados para os picos das Figuras 1 e 2 .

Para verificar a especificidade da interação, um controle foi preparado adicionando-se anticorpos antiMLR sobre a mica funcionalizada com MLR, antes da análise. A curva de força para este controle foi medida utilizando uma ponta funcionalizada com anticorpos (antiMLR). Como resultado, as curvas de aproximação e de retração apresentaram traçados idênticos (Figura 4a). Nota-se claramente que na curva de força do controle não houve nenhuma atração durante o contato ponta/substrato, devido à ausência de forças de interação. Portanto, qualquer modificação nessas características da curva, onde não haja um bloqueio de sítios antigênicos, pode conter informações importantes de interação específica Ac-Ag.

Medidas de força foram feitas no modo de contato em tampão fosfato de sódio $20 \times 10^{-3} \mathrm{~mol} \mathrm{~L}^{-1}$, a partir da interação entre sítios contendo microcistina que foram identificados nas imagens de varredura. Em todos os experimentos, a ponta do AFM foi aproximada da superfície da amostra permitindo a formação do complexo

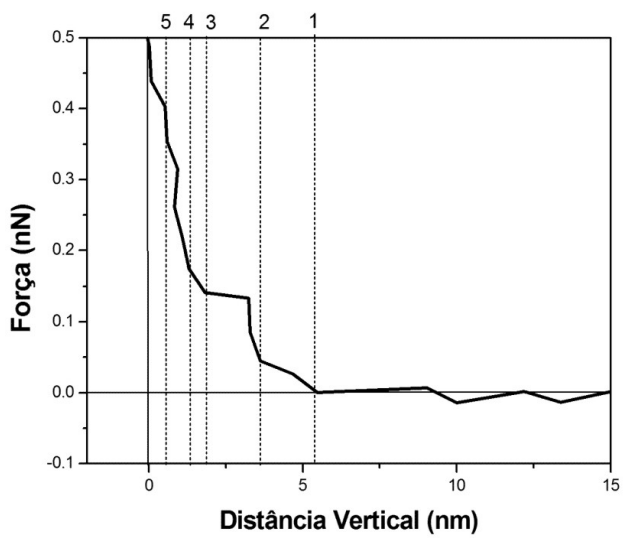

Figura 3. Análise de uma curva de aproximação feita com uma ponta funcionalizada com anticorpos. Detalhes da curva demonstram a existência de materiais de constituição química diferente, evidenciados pela força que deve ser aplicada para que a ponteira atravesse as diferentes camadas dispostas a o longo do eixo entre a ponta e o substrato. As linhas verticais numeradas sugerem limites de separação entre as camadas de diferentes materiais

anticorpo-antígeno. Após o contato entre ponta e amostra, ambas são afastadas aplicando-se uma força crescente para separar a ponta (anticorpo) da superfície que contém a amostra (microcistina). Durante o afastamento o complexo antígeno-anticorpo é esticado até o momento de ruptura.

Os resultados demonstram que ligações específicas entre Ag-Ac foram rompidas quando a ponta é afastada da superfície pela aplicação de uma força com magnitude suficiente para quebrar essas forças de interação. A força de ruptura é chamada de força de desacoplamento $\mathrm{f}_{\mathrm{u}}$ (força máxima exercida entre receptor-ligante), ${ }^{19}$ sendo aqui calculada a partir de valores médios obtidos a partir de 30 determinações de curvas de força. $\mathrm{O}$ evento de desacoplamento é caracterizado por um pulo abrupto na curva de força para uma posição neutra como apresentado na Figura 4b. A Figura 4c apresenta os histogramas associados às determinações.

De uma curva de força de atração, pode-se tirar outra informação importante: o comprimento total da ligação estendida entre a ponta e a superfície da amostra, que é definido como sendo o comprimento de desacoplamento $\left(1_{\mathrm{u}}\right) \cdot{ }^{19}$

Quando há interação química entre a ponta e a amostra, a curva de retração caracteriza um ou mais eventos de adesão, apresentando componentes com valores negativos, como o resultado da Figura 4b. Observam-se nesta curva de retração dois eventos demonstrando a interação entre anticorpos ligados à ponta com antígenos fixados na superfície da mica. A Figura 2S (material suplementar) apresenta algumas configurações possíveis para o sistema, onde várias moléculas de anticorpos do tipo imunoglobulina $\mathrm{G}(\mathrm{IgG})$ podem estar ligadas à ponta e as possibilidades de interação entre anticorpos e antígenos. $\mathrm{O}$ esquema da Figura $2 \mathrm{~S}$ (material suplementar) leva em consideração a reação de funcionalização que prevê a ligação do anticorpo ao glutaraldeído através de aminoácidos básicos presentes na proteína. A estrutura tridimensional de anticorpos foi obtida a partir da base de dados de proteínas (PDB). ${ }^{20}$

O perfil da curva de retração (Figura 4b) tem sido reportado em diversos sistemas, sendo chamado de dente de serra, evidenciando, no caso de proteínas, a presença de módulos repetitivos sofrendo desnaturação e renaturação. ${ }^{21}$ No presente trabalho, o perfil do dente de serra e a magnitude das forças de adesão sugerem a existência de múltiplos pontos de contato entre a ponta funcionalizada e o substrato. Tomando como base o trabalho de Oberhauser et $a l .{ }^{21}$ uma interpre- 

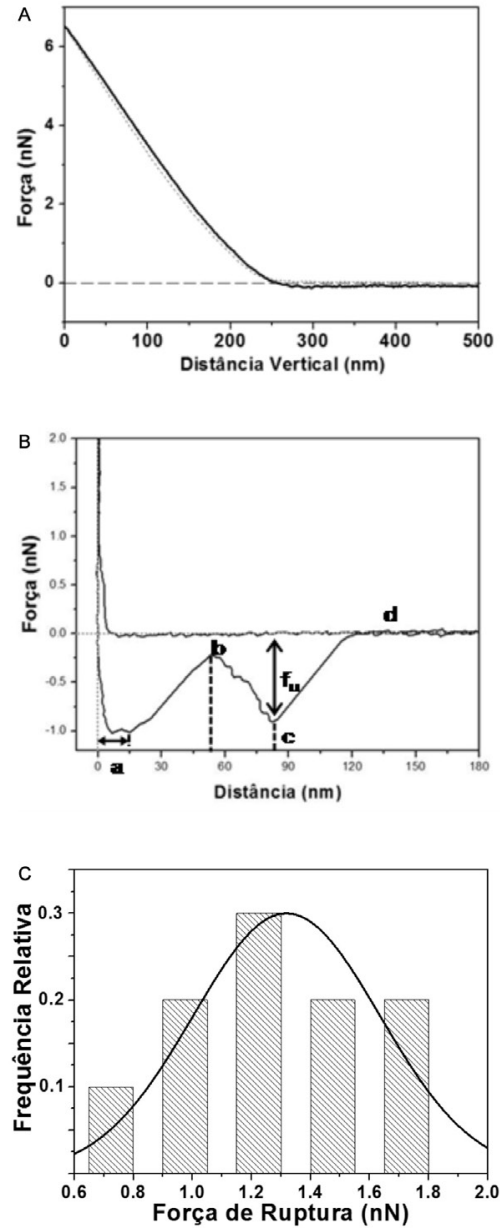

Figura 4. Curvas de força medidas por AFM em meio líquido. Na curva controle (A) os sítios antigênicos foram totalmente bloqueados pela incubação com anticorpo antes das medidas. Curva de aproximação em linhas pontilhadas e curva de retração (afastamento) em linha cheia. A interação específica entre anticorpo e antígeno é demonstrada através da curva de força (B). A curva de retração mostra a adesão entre a sonda e a amostra. Detalhes indicam a determinação da força de desacoplamento $\left(f_{u}\right)$ e comprimento da ligação estendida $\left(l_{u}\right)$. Os pontos " $a, b$, c e d" indicam eventos da curva de retração explicados no texto. Histogramas associados à curva de força média estão apresentados em $(C)$

tação simples seria a de alongamento da ligação e desnaturação de vários complexos anticorpo-antígeno formados no primeiro evento, seguido de uma renaturação e ruptura de todos os complexos ao final do segundo evento. Os valores obtidos para forças de interação, $\sim 1000$ pN no primeiro evento e $\sim 700$ pN no segundo, quando comparados com dados da literatura, de onde se deduz que a força média para a interação anticorpo-antígeno é da ordem de $240 \mathrm{pN}$, sugerem a existência, no primeiro evento, de aproximadamente $4 \mathrm{e}$ no segundo, de aproximadamente 3 interações específicas (anticorpomicrocistina). ${ }^{18-21}$ Medidas de força determinadas para um sistema enzima-substrato apresentam valores mais altos, cerca de $1000 \mathrm{pN} .{ }^{21}$

Tomando como base a curva da Figura $4 b$ pode-se identificar 4 pontos de interesse (a-d). Em (a) a ligação é submetida a uma força de aproximadamente $1000 \mathrm{pN}$, esticando aproximadamente $4 \mathrm{com}$ plexos anticorpo-antígeno por cerca de $15 \mathrm{~nm}$. Esta força provoca um rearranjo no sistema sugerindo um efeito de desnaturação de uma ou mais proteínas (anticorpos). Ao perder a forma nativa, os anticorpos assumem uma conformação mais alongada (semelhante a uma mola esticada). Devido à desnaturação (estiramento da proteína) há um relaxamento e a ponta funcionalizada retorna a uma posição perto do equilíbrio (ponto b). A partir deste ponto, novas ligações são submetidas a um alongamento, segundo o percurso b-c. Há novamente um incremento da força até $\sim 700 \mathrm{pN}$, indicando por (c). Neste caso, a interação ponteira-substrato foi alongada até um ponto de ruptura e a alavanca retorna à posição de equilíbrio indicada por (d).

Os resultados apresentados demonstram o grande potencial que o biossensor construído pode representar para as áreas de monitoramento ambiental, saúde e segurança pública. Foi demonstrada a detecção de microcistina-LR a nível molecular, sugerindo que outras substâncias tóxicas também poderiam ser avaliadas a partir da conjugação de sistemas imunológicos a um atuador químico, como a alavanca do microscópio de força atômica.

Concluindo, este estudo vem adicionar mais um método de detecção de cianotoxinas aos já conhecidos, providenciando uma detecção sensível (a nível molecular), rápida e fácil de ser reproduzida a partir de uma padronização prévia.

\section{MATERIAL SUPLEMENTAR}

A Figura $1 \mathrm{~S}$ referente à estrutura e dimensões para microcistina, glutaraldeido e APTES, assim como a Figura 2S, referente às dimensões da ponteira funcionalizada com anticorpos e sua interação com o substrato; a Figura 3S, referente à imagem topográfica de APTES sobre a mica e Figura 4S, que apresenta a vista em perspectiva das imagens topográficas da microcistina com ponta normal e funcionalizada estão disponíveis em http://quimicanova.sbq.org.br na forma de arquivo PDF, com acesso livre.

\section{AGRADECIMENTOS}

C. de C. Bueno recebeu bolsas do Fundo de Apoio à Iniciação Científica-FAPIC/Reitoria-Pontifícia Universidade Católica de Campinas e PIBIC/CNPq. Este trabalho foi financiado com fundos provenientes da Propesq (PUC-Campinas) e Fapesp (2003/0054-0). Agradecemos pela expressiva contribuição do Sr. L. Bonugli nas medições de AFM e ao Sr. J. R. Castro pela assistência técnica.

\section{REFERÊNCIAS}

1. Jochimsen, E. M.; Carmichael, W. W.; An, J. S.; Cardo, D. M.; Cookson, S. T.; Holmes, C. E. M.; Antunes, M. B. D.; de Melo, D. A.; Lyra, T. M.; Barreto, V. S. T.; Azevedo, S. M. F. O.; Jarvis, W. R.; N. Engl. J. Med. 1998, 338, 873

2. Metcalf, J. S.; Bell, S. G.; Codd, G. A.; Appl. Environ. Microbiol. 2001, 67, 904; Mayumi, T.; Kato, H.; Imanishi, S.; Kawasaki, Y.; J. Antibiot. 2006, 59, 710 .

3. Ueno, Y.; Nagata, S.; Tsutsumi, T.; Hasegawa, A.; Watanabe, M.F.; Park, H.-D.; Chen, G.-C.; Chen, G.; Yu, S.-Z.; Carcinogenesis 1996, 17, 1317.

4. Bell, S. G.; Codd, G. A.; Environ. Sci. Technol. 1996, 5, 109; Campbell, D. L.; Lawton, L. A.; Beattie, K. A.; Codd, G. A.; Environ. Toxicol. 1994, 9, 71 .

5. Carmichael, W. W.; J. Appl. Bacteriol. 1992, 72, 445.

6. Tonk, L.; Visser, P. M.; Chistiansen, G.; Snelder, E. O. F. M.; Weidner, E.; Mur, L. R.; Huisman, J.; Appl. Environ. Microbiol. 2005, 71, 5177.

7. Etchegaray, A.; Silva-Stenico, M. E.; Moon, D. H.; Tsai, S. M.; Microbiological Research 2004, 159, 425.

8. Hu, S.; Li, P. C. H.; Analyst 2001, 126, 1001.

9. Chu, F. S.; Huang, X.; Wei, R. D.; Carmichael, W. W.; Appl. Environ. Microbiol. 1989, 55, 1928.

10. Ma, W.; Chen, W.; Qiao, R.; Liu, C.; Yang, C.; Li, Z.; Xu, D.; Peng, C.; Jin, Z.;Xu, C.; Zhu, S.; Wang, L.; Biosens. Bioelectron. 2009, 25, 240.

11. Ferreira, A. A. P.; Yamanaka, H.; Quim. Nova 2006, 29, 137. 
12. Grandbois, M.; Dettmarkn, W.; Benoit, M.; J. Histochem. Cytochem. 2000, 48, 719; Walch, M.; Ziegler, U.; Groscurth, P.; Ultramicroscopy 2000, 82, 259.

13. Kienberger, F.; Ebner, A.; Gruber, H. J.; Hinterdorfer, P.; Acc. Chem. Res. 2006, 39, 29; Lee C. K.; Wang Y. M.; Huang L. S.; Lin S.; Micron 2007, 38, 446; Chen, G.; Zhou, J.; Park, B.; Xu B.; Appl. Phys. Lett. 2009, 95, 043103; Braunschweig, A. B.; Elnathan, R.; Willner, I.; Nano Lett. 2007, 7, 2030.

14. Wang, H.; Bash, R.; Yodh, J. G.; Hager, G. L.; Lohr, D.; Lindsay, S. M.; Biophys. J. 2002, 83, 3619; Baumgartner, W.; Hinterdorfer, P.; Ness, W.; Raab. A.; Vestweber, D.; Schindler, H.; Drenckhahn, D.; Proc. Natl. Acad. Sci. U. S. A. 2000, 97, 4005; Hinterdorfer, P.; Baumgartner, W.; Gruber, H. J.; Schilcher, K.; Schindler, H.; Proc. Natl. Acad. Sci. U. S. A. 1996, 93, 3477.

15. Sader, J. E.; Chon, J. W. M.; Mulvaney, P.; Rev. Sci. Instrum. 1999, 70, 3967.

16. Peng, C.; Song, S.; Fort,T.; Surf. Interface Anal. 2006, 38, 975; Spagnoli, C.; Loos, K.; Ulman, A.; Cowman, M. K. J.; J. Am. Chem. Soc. 2003, 125, 7124.
17. http://www.pdb.org/pdb/explore/jmol.do?structureId=1EVB, acessada em Abril 2010; Bagu, J. R.; Sönnichsen, F. D.; Williams, D.; Andersen, R. J.; Sykes, B. D.; Holmes, C. F.; Nat. Struct. Mol. Biol. 1995, 2, 114.

18. Morris, V. J.; Kirby, A. R.; Gunning, A. P. Em Atomic force microscopy for biologists; Morris, V. J.; Kirby, A. R.; Gunning, A. P., eds.; Imperial College Press: London, 2004, chap. 3.

19. Hinterdorfer, P.; Schilcher, K.; Baumgartner, W.; Gruber, H. J.; Schindler, H.; Nanobiology 1998, 4, 177.

20. http://www.pdb.org, consultada em Abril 2010; Wilson, I. A.; Stanfield R. L.; Curr. Opin. Struct. Biol. 1994, 4, 857.

21. Oberhauser, A. F.; Marszalek, P. E.; Erickson; H. P.; Fernandez, J. M.; Nature 1998, 393, 181; Gilbert, Y.; Deghorain, M.; Wang, L.; Xu, B.; Pollheimer, P. D.; Gruber, H. J.; Errington, J.; Hallet, B.; Haulot, X.; Verbelen, C.; Hols, P.; Dufrêne, Y. F.; Nano Lett. 2007, 7, 796; Willemsen, O. H.; Snel, M. M. E.; van der Werf, K. O.; de Grooth, B. G.; Greve, J.; Hinterdorfer, P.; Gruber, H. J.; Schindler, H.; van Kooyk, Y.; Figdor, C. G.; Biophys. J. 1998, 75, 2220. 


\section{IDENTIFICAÇÃO DE MICROCISTINA LR AO NÍVEL MOLECULAR EMPREGANDO MICROSCOPIA DE FORÇA ATÔMICA}

Augusto Etchegaray* e Carolina de Castro Bueno

Faculdade de Química, Pontifícia Universidade Católica de Campinas, CP 317, 13012-970 Campinas - SP, Brasil

Omar Teschke

Instituto de Física Gleb Wataghin Universidade Estadual de Campinas, CP 6165, 13083-970 Campinas - SP, Brasil

\section{A} $\sim 2,5 \mathrm{~nm}$

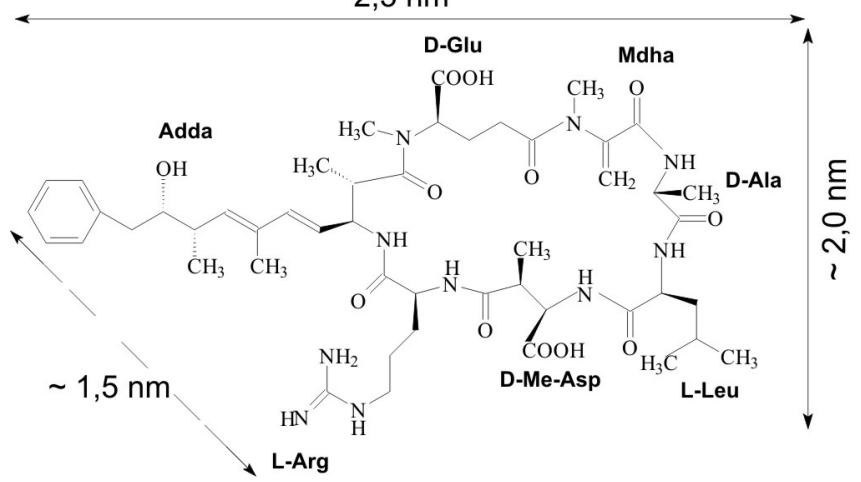

B<smiles>CCO[Si](CCCN)(OCC)OCC</smiles>

C

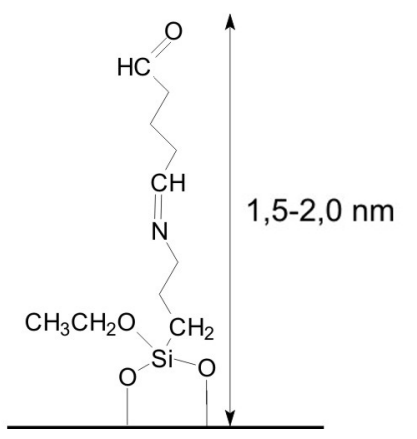

Figura 1S. Estruturas e dimensões aproximadas para microcistina, APTES e glutaraldeído: (A) estrutura da microcistina leucina-arginina (MLR), ciclo (-DALA-LEU-D-metil-ASP-ARG-ADDA-D-GLU-MDHA). ${ }^{5} M L R$ é um peptídeo não ribossômico, evidenciado por sua estrutura cíclica, pela presença de aminoácidos não proteicos (ácido 3-amino-9-metoxi-10-fenil-2,6,8-trimetil-deca-4,6-dienoico (ADDA), ácido D-eritro-beta-metil-aspártico e N-metil-desidro-alanina (MDHA)) e, também pela formação de ligações peptídicas não convencionais. A ligação amida entre o ácido metil-aspártico e o resíduo de arginina é feita com a carboxila da cadeia lateral do ácido aspártico. Da mesma forma, a ligação amida entre o resíduo de desidro-alanina e o ácido glutâmico envolve a ligação à carboxila da cadeia lateral do ácido glutâmico. A estrutura tridimensional da MLR está disponível na base de dados de proteínas (PDB), onde se pode inferir os valores de dimensão da molécula aqui indicados. ${ }^{15} \mathrm{Em}(B)$ e $(C)$ apresentam-se as estruturas e dimensões aproximadas para APTES e glutaraldeído (B) e para o conjugado (APTES-glutaraldeído) ligado à mica $(C)$ 


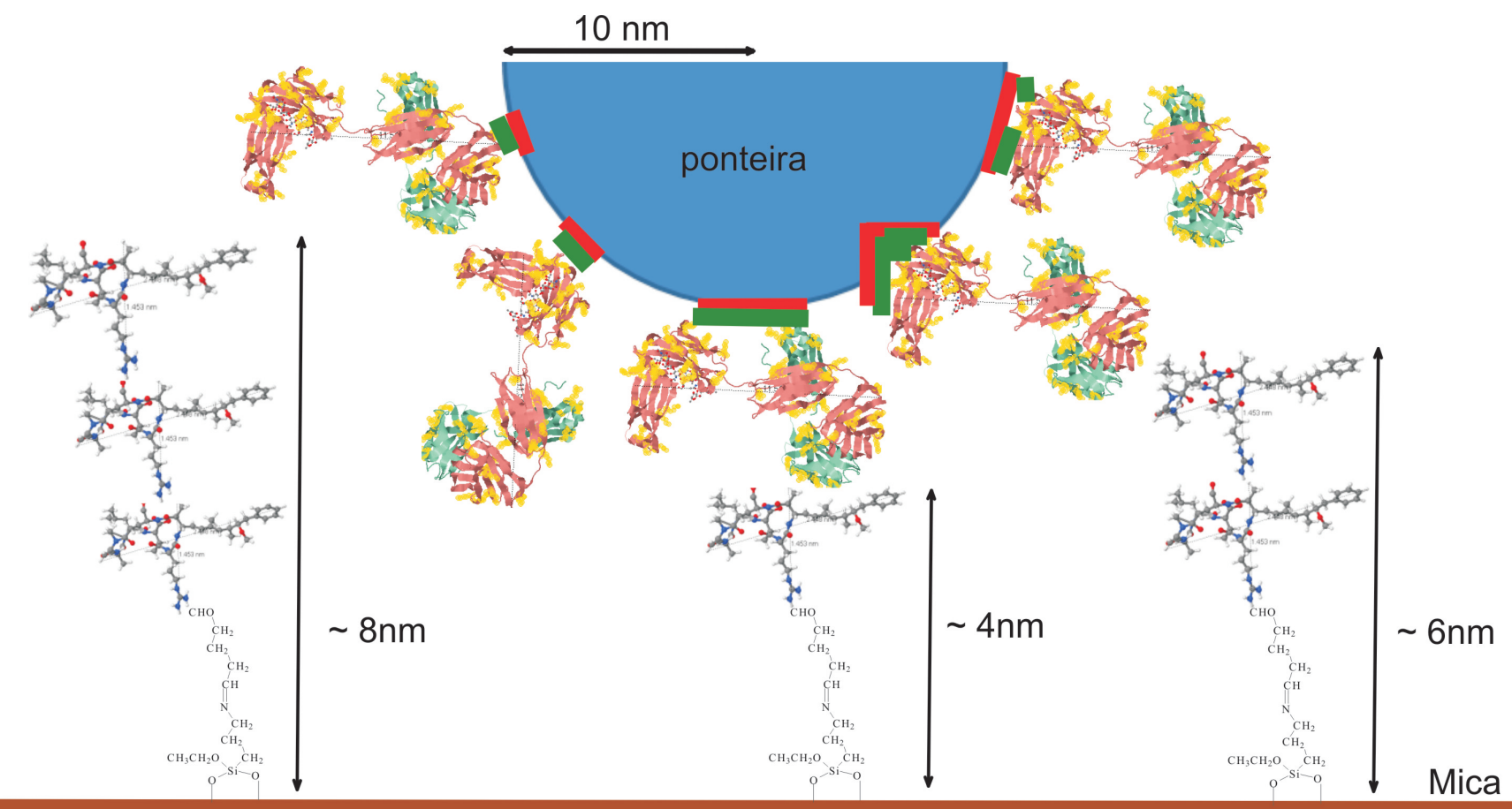

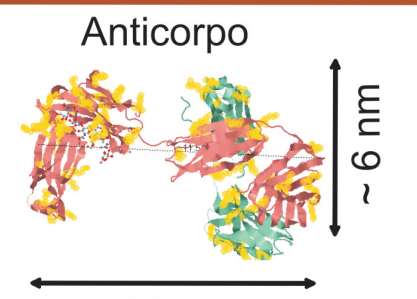

$\sim 10 \mathrm{~nm}$

\section{Microcistina LR}

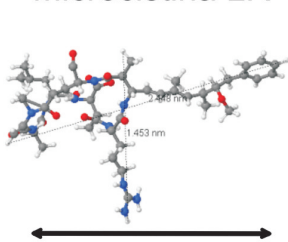

$\sim 2,5 \mathrm{~nm}$

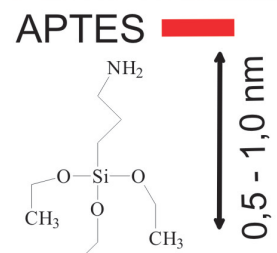

$\mathrm{CH}_{3}$

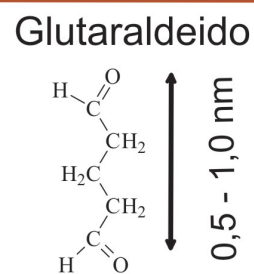

Figura 2S. Esquema representativo para o sistema ponta funcionalizada-substrato. Todos os materiais estão aproximadamente na mesma escala, com os valores de dimensões aproximados. Analisando a ponteira, considera-se que após tratamento houve formação de uma monocamada de APTES, recoberta com uma monocamada de glutaraldeído (conforme legenda de cores). As estruturas para microcistina e anticorpo estão disponíveis na base de dados de proteínas. ${ }^{15,20}$ Detalhes em laranja na estrutura dos anticorpos denotam os sítios onde existem aminoácidos básicos, disponíveis para fixação ao glutaraldeído, durante a funcionalização da ponteira. De acordo com a figura, uma molécula de microcistina ligada a uma estrutura em monocamada de APTES-glutaraldeído teria a dimensão de $4 \mathrm{~nm}$, conforme indicado. Demais arranjos são representações considerando associações iônicas entre moléculas de microcistina, produzindo estruturas de 6 e $8 \mathrm{~nm}$, respectivamente 

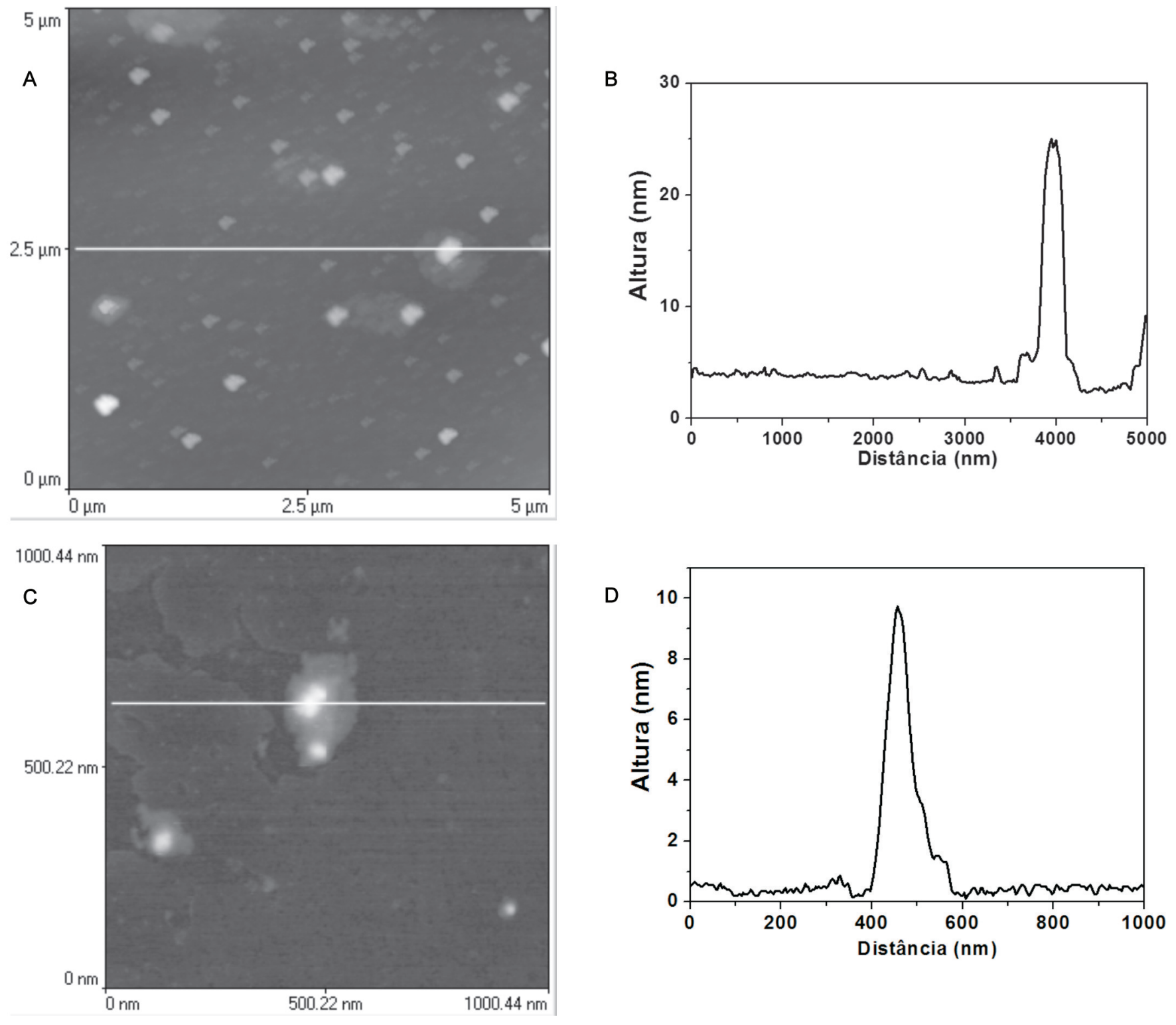

Figura 3S. Imagens topográficas da mica recoberta com APTES: (A) imagem e (B) perfil do substrato tratado diretamente com $5 \mu L$ de APTES; (C) imagem e (D) perfil do substrato após tratamento com vapores de APTES, seguido da ligação de glutaraldeído e microcistina 


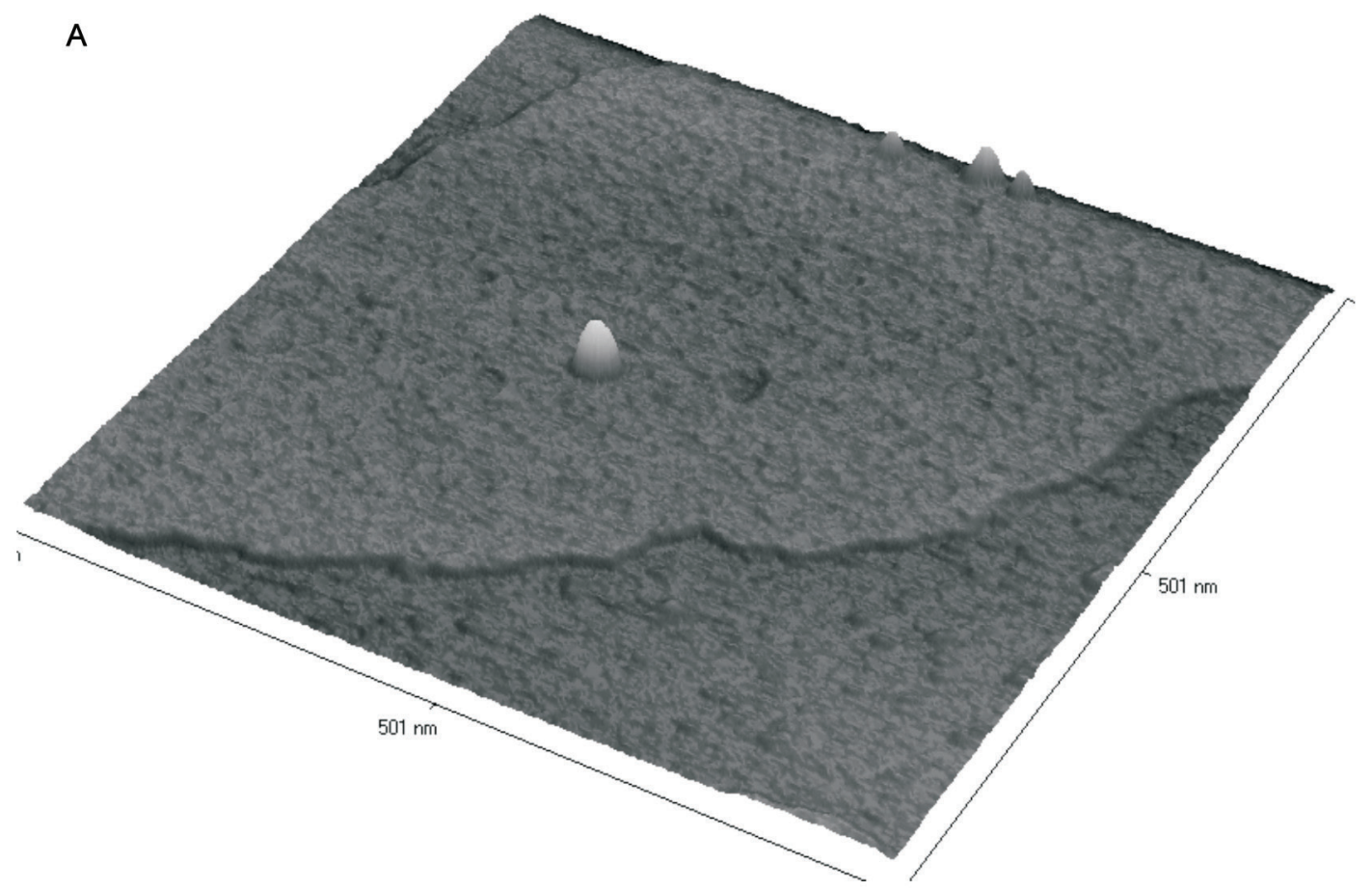

\section{B}

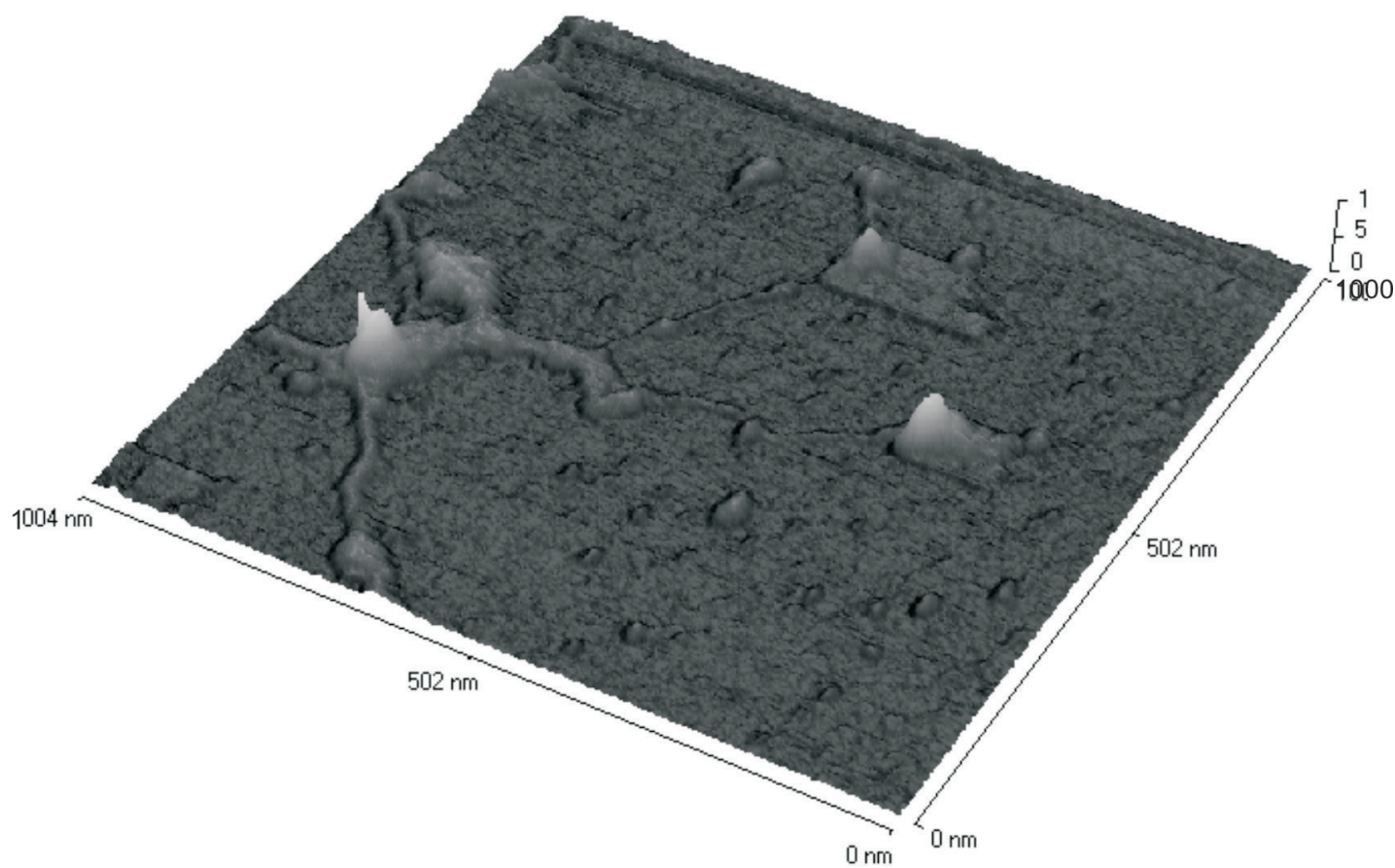

Figura 4 S. Vista em perspectiva das imagens topográficas da varredura do substrato funcionalizado com APTES, glutaraldeído e microcistina: (A) imagem tridimensional da Figura 1, correspondendo à varredura com ponta normal e (B) imagem tridimensional da Figura 2; varredura com ponta funcionalizada com anticorpos 